\title{
Bone regeneration with autologous dentin: a case report and histological analysis
}

\begin{abstract}
Introduction: Bone regeneration in post-extraction sockets has been frequently used with bone grafts, some authors have proposed the use of autologous dentin as a substitute for these bone grafts.
\end{abstract}

Materials and methods: An extraction and an autologous dentin regeneration was performed in a 28 -year-old patient on tooth 21 , it was evaluated radiographically at 9 months and subsequently histological study, to evaluate the results at a microscopic level.

Results: Clinically good tissue integration was observed. In the biopsy, a physiological bone remodeling was observed, where the dentin particles are biologically integrated with the adjacent alveolar bone.

Discussion: Bone crest volume was preserved, soft tissues healed properly and without any signs of inflammation

Conclusions: In this case report, an adequate integration of dentin with the patient's bone tissues was observed. There is still limited evidence on the use of autologous dentin as a bone substitute, controlled clinical trials are required to assess the outcome of the implementation of its use.
Volume II Issue 2 - 2020

\author{
Jaime Andrés Montoya Pereira,' Lina Marcela \\ Herrera Orozco,' Rubiel Antonio Marín \\ Jaramillo ${ }^{2}$ \\ 'Dentist, Periodontist, CES University, Colombia \\ ${ }^{2}$ Dentist, Periodontist, Master of Dental Sciences, PhD \\ Candidate in Epidemiology and Biostatistics, CES University, \\ Colombia
}

\begin{abstract}
Correspondence: Rubiel Antonio Marín Jaramillo, Dentist, Periodontist, Master of Dental Sciences, PhD Candidate in Epidemiology and Biostatistics, CES University, Colombia,Tel +5744440555, Email rmarin@ces.edu.co
\end{abstract}

Received: March 10, 2020 | Published: April 07, 2020

\section{Introduction}

It has been established that the extraction of a tooth is followed by an imminent reduction of the horizontal and vertical dimension of the alveolar bone, ${ }^{1,2}$ and in addition to that bone resorption occurs especially in vestibular of anterior teeth and premolars, where the bone is thinner. ${ }^{3,4}$ Different therapeutic alternatives have been proposed in recent decades for bone regeneration, including autologous bone grafts, allografts, xenografts and alloplastic materials. ${ }^{5}$

Since 1942, an experimental study in dogs reported the histological reactions of the tissue in the presence of root fracture, finding pulp vitality after the healing period. Additionally, it was observed in some dogs that the coronal part of the pulp was protected by epithelial gingival growth. In 1961, Björn described the technique of root immersion to preserve the volume of the alveolar bone in patients using complete dentures, finding that the height of the ridge was maintained after performing the procedure. ${ }^{6}$ Recently, new surgical techniques have been described, such as the "socket shield" technique, in which the vestibular wall of the tooth to be extracted is preserved inside the socket, in order to prevent the resorption of the vestibular bundle bone. ${ }^{7,8}$

The application of autologous dentin, as a bone substitute for a ridge augmentation procedure, has been described as an alternative to avoid biomaterials. ${ }^{9}{ }^{10}$ since the organic and inorganic component of said tissue resembles the properties of the bone. ${ }^{11}$ Histological studies have reported that dentin contains osteonectin, osteocalcin, bone sialoprotein and osteopontin that are important proteins for bone formation and differentiation. ${ }^{12,13}$

Recent studies have evaluated bone regeneration with autologous dentin and subsequent implant placement, with follow-up to 12 and 24 months, showing implants in appropriate conditions and without complications. ${ }^{14,15}$

\section{Materials and methods}

28-year-old male patient, dental and skeletal Angle class II, ${ }^{16}$ ASA I, ${ }^{17}$ smoker of $<10$ cigarettes a day, with orthodontic treatment since 2010, with little adherence to therapy, and periodontal disease; presenting tooth 21 with Samet \& Jotkowitzprognosis, ${ }^{18}$ due to an initial caries that evolved to a crown fracture and a residual root which had to be endodontically treated, and currently has a healthy apex (Figure 1). ${ }^{19}$

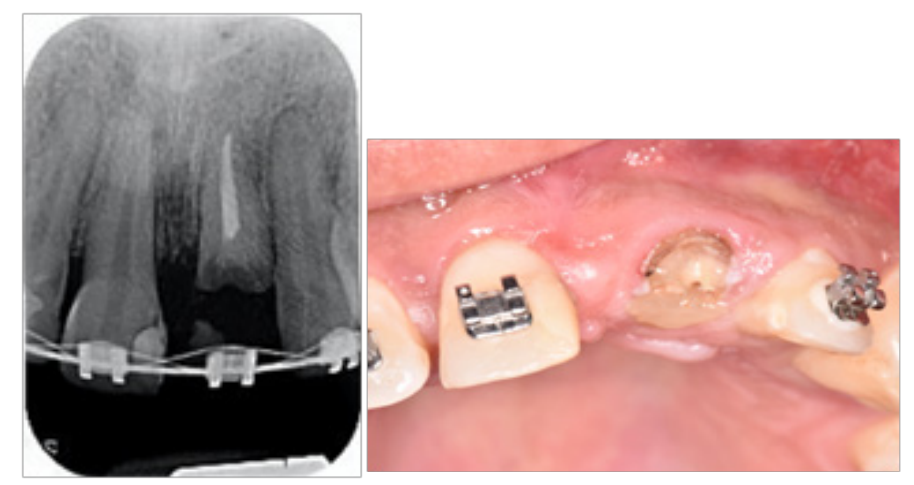

Figure I Initial clinical and radiographic situation.

The treatment plan consisted of periodontal therapy, fixed provisionalization of tooth 21 , orthodontic activation for space closure and orthodontic extrusion of tooth 21 , removing the filling from the root canal of tooth 21 and coronal seal, dental extraction and preservation of residual ridge using particles of the dentin from the extracted tooth. The patient fully understood the nature of the proposed treatment and signed an informed consent.

The surgical field was prepared following the protocols of asepsis and antisepsis, anesthesia with articaine $4 \%$ epinefrine $1: 100,000$ in the surgical area (tooth 21). Atraumatic removal of the residual root 
(tooth 21) without flap elevation (Figure 2). Curettage of the socket and irrigation with chlorhexidine $0.12 \%$. With magnification root cement was removed from the root extracted with diamond burrs (previously treated endodontically and filling free). The root was crushed with bone crusher to create a particulate material of approximately $450 \mu$ (Figure 3). Mixing of the particulate material with patient's blood to hydrate graft (Figure 4). Full thickness flap in vestibular from 1121-22. An incision was made on the palate to obtain a connective tissue graft and epithelium (Inlay-Onlay), which was fixed with nonabsorbable suture (Cytoplast ${ }^{\circledR}$ 4-0) at the extraction site to use as a biological membrane and favor a seal (Figure 5). The socket was filled with dentin graft (Figure 6), It was sutured to ensure a primary wound closure with non-absorbable suture (Figure 7), and an immediate periapical X-ray was taken after the procedure was finished (Figure $8)$.

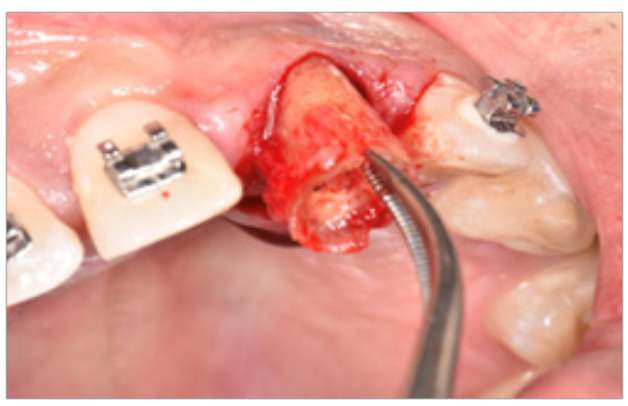

Figure 2 Atraumaticextraction.
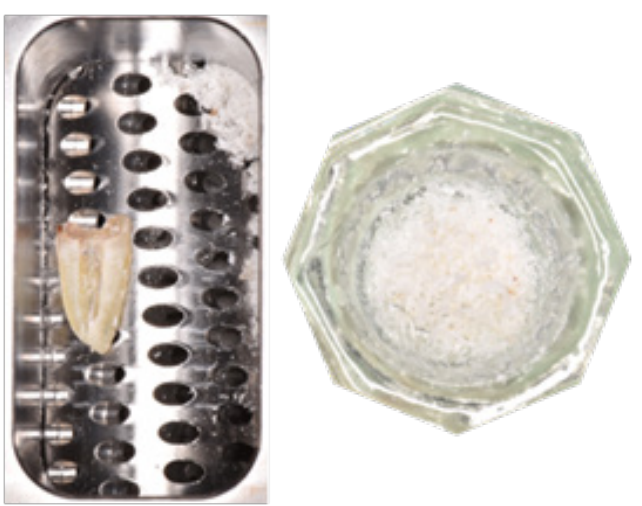

Figure 3 Crushed root without root cement.

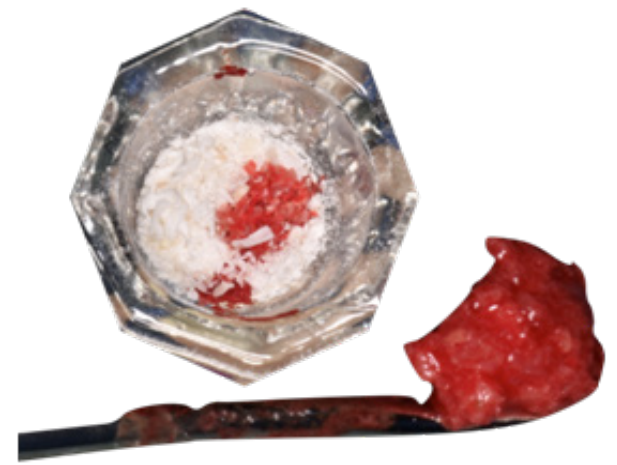

Figure 4 Dentine particles hydrated with blood.

The patient was prescribed with Amoxicillin cap 500mg every 8 hours for 7 days, Meloxicam tab $15 \mathrm{mg}$ every 24 hours for 5 days, chlorhexidine Gluconate rinses $0.12 \%$ twice a day for 10 days and spray with triticum vulgare (fitoestimuline ${ }^{\circledR}$ ) 4-6 times a day for
15 days. Post-surgical review was performed 7 and 14 days after the procedure. The sutures were removed 14 days later (Figure 9). The patient attended periodontal control every 3 months after the procedure.

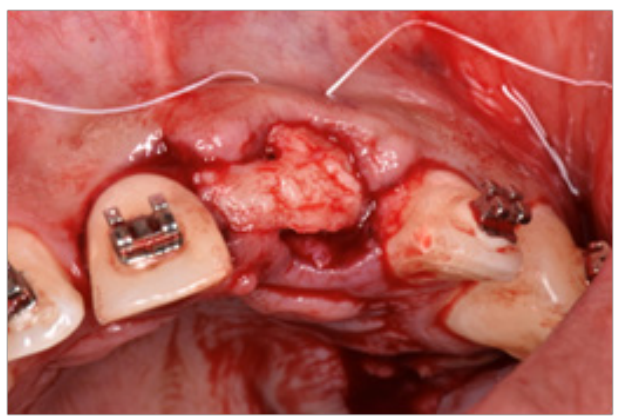

Figure 5 Inlay-Onlay graft.

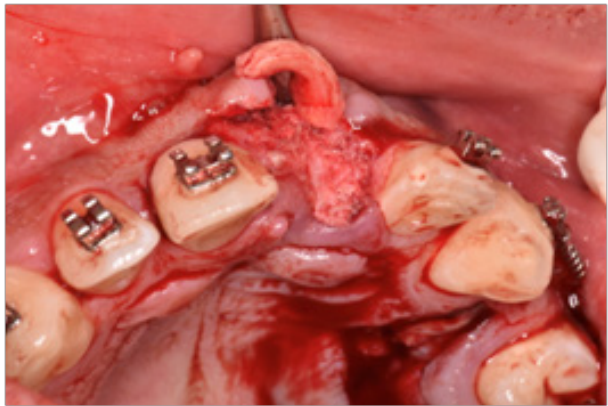

Figure 6 Dentin particles in the socket.
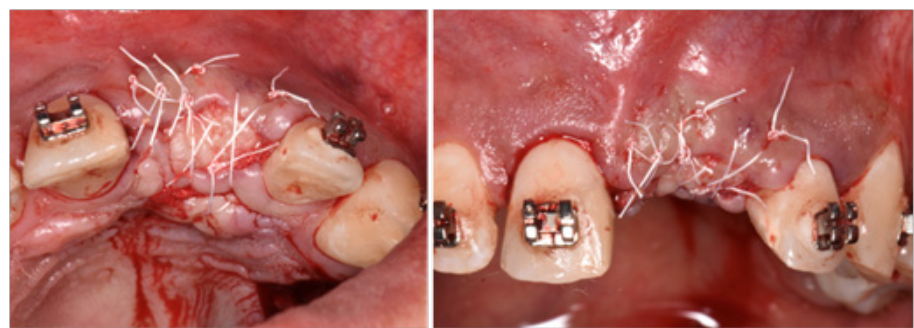

Figure 7 Sutures.

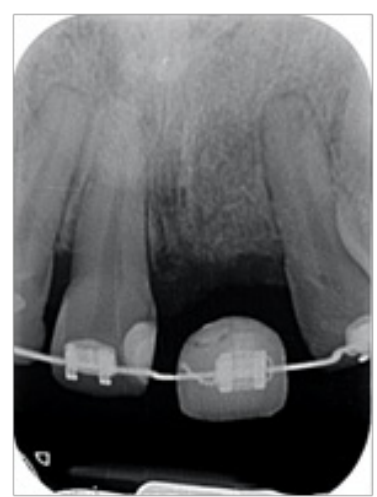

Figure 8 Immediate post-surgical X-ray.

After 9 months after the procedure, it was decided to perform a biopsy of the grafted site, implant planning was not performed since the patient has not yet finished closing spaces with orthodontics. The soft tissue was observed in optimal conditions and the gingival margin of the edentulous area was healthy (Figure 10). 


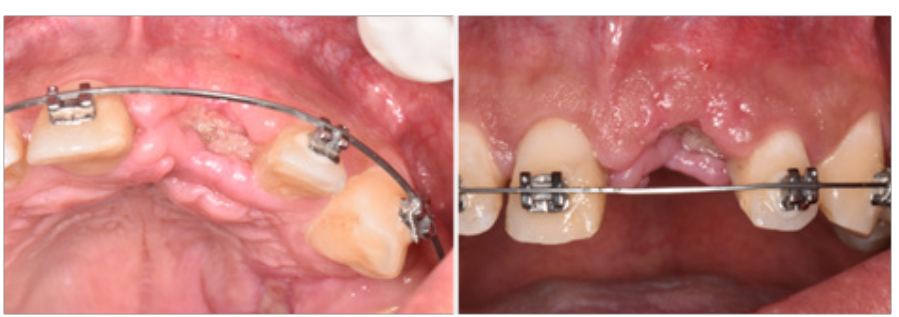

Figure 9 Healing 15 days.

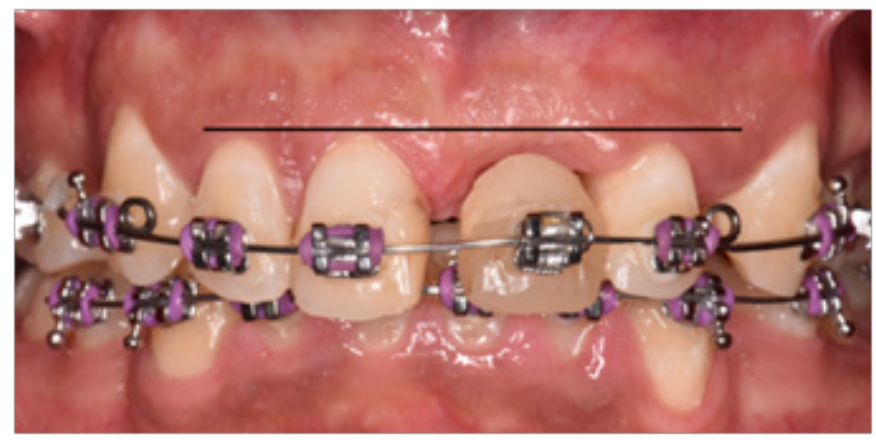

Figure 109 months of healing.

\section{Results}

CT scan of the area was performed to verify graft integration. With local anesthesia, a full thickness flap was raised in the area of tooth 21 to obtain a $2 \mathrm{~mm}$ diameter biopsy by means of the use of a trephine, which was sent to the laboratory for histological study.

\section{Clinical evaluation}

After tooth extraction and preservation of the bone ridge with dentin particles, healing proceeded without complications or signs of reaction to a foreign body. The soft tissues closed completely after 2 weeks and remained stable until 9 months of healing.

\section{Radiographic and tomographical evaluation}

Intraoral X-ray show the compromised tooth at the start of the study and the post-extraction socket containing dentin particles. After 9 months of healing, the hard sheet disappeared completely and the area previously grafted with dentine particles acquired the same appearance as the surrounding bone tissue (Figure 11). The CT scan performed 9 months after the procedure revealed the preservation of the alveolar crest. The vestibular bone table was reabsorbed, but the dentin graft could compensate for the marginal bone remodeling. The anterior cavity seemed to be completely filled with new mineralized tissue.

\section{Histological evaluation}

It was decided to obtain a biopsy of the area to confirm tissue formed 9 months after surgery (Figure 12). The bone section shows dentin fragments partially or completely surrounded by newly formed bone (Figure 13). The newly formed bone joins the single root fragments. The spaces between the root and bone fragments are filled with connective tissue and vessels. No inflammatory reaction is evident. When a cross section of the biopsy sample cone is examined, the connective tissue is evident, indicating that physiological bone remodeling is taking place that affects both the root fragments and the bone. Root fragments contain dentin areas and no cement was reported. The newly formed bone has an obvious intimate contact with the dentin, which evidences biological compatibility. The newly formed bone areas along the dentin fragments show osteocytes in the bone. On the surface of the bone, an osteoid layer and bone-forming osteoblasts are evident, indicating continuous bone formation.

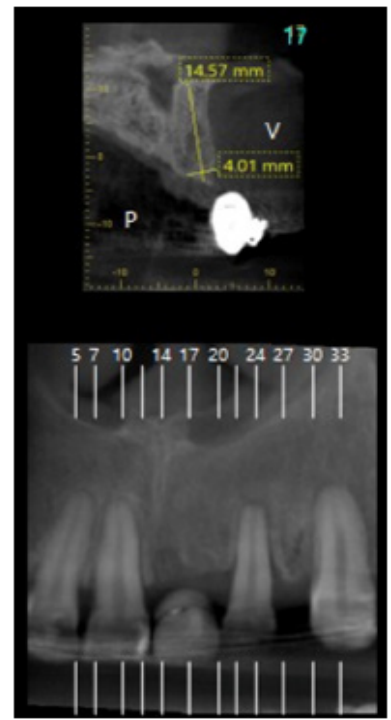

Figure II CT scan 9 months after intervention with dentin particles.

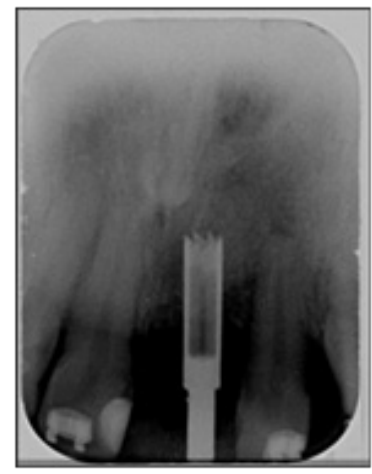

Figure 12 X-ray biopsy guide.
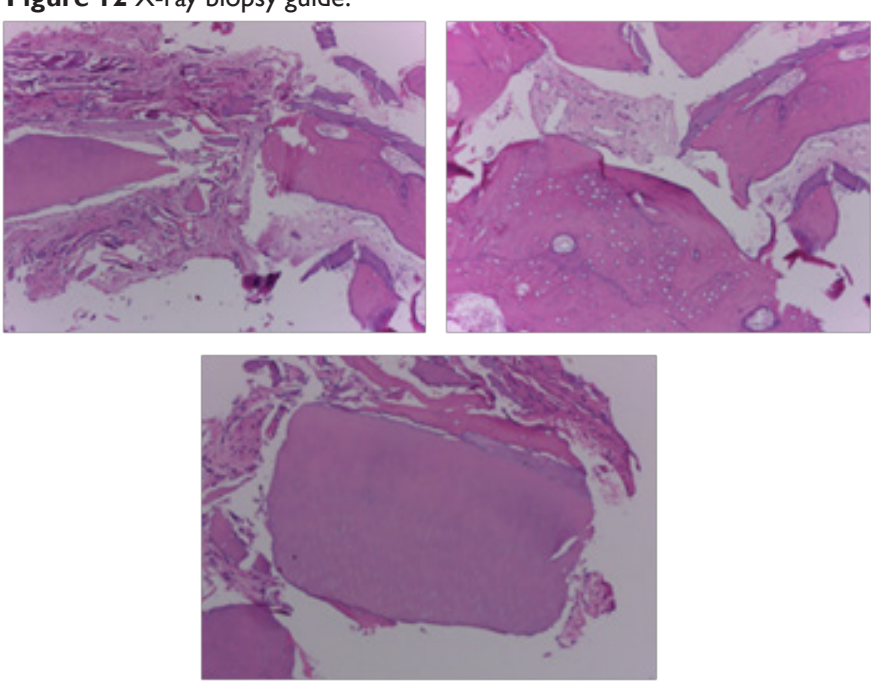

Figure 13 Biopsy. 


\section{Discussion}

The objective of this case report was to report the use of dentin particles used for the preservation and regeneration of bone from the extracted site. Clinical reentry at 9 months revealed that the graft was incorporated and stimulated the formation of new bone in the socket. Bone crest volume was preserved, soft tissues healed properly and without any sign of inflammation. These positive findings corroborate the results reported by other authors ${ }^{6-8}$ as biomaterials for bone regeneration or preservation of the bone ridge.

From a clinical point of view, extracted teeth can be used as well as grafts, blocks or particles. The extracted dental roots have been used as blocks to preserve bone volume in other clinical studies, ${ }^{8}$ revealing a structural and biological potential to serve as an alternative autograft for bone regeneration or preservation of the alveolar ridge, and additionally without representing an extra cost to the patient. As the dentin graft maintains the structure of the collagen, it appears to be able to preserve both the height and width of the bone ridges, suggesting that dentine graft can be used as an autogenous biomaterial useful for bone ridge preservation. ${ }^{20,21}$

\section{Conclusion}

There are limitations in the available studies and limitation for the non-adherence to orthodontic treatment of this patient. This proposal could be considered as an alternative regenerative therapy. With the results obtained in the biopsy, it could be said that it could be feasible to perform the insertion of an implant, however, as in many cases of bone regeneration, some additional graft may be needed at the time of said intervention. The volume has been maintained over time, suggesting that dentin could be used as bone filling material.

\section{Funding}

None.

\section{Acknowledgments}

None.

\section{Conflicts of interest}

None.

\section{References}

1. Schropp L, Wenzel A, Kostopoulos L, et al. Bone healing and soft tissue contour changes following single-tooth extraction: a clinica and radiographic 12-month prospective study. Int $J$ Periodontics Restorative Dent. 2003;23(4):313-323.

2. Araújo MG, Lindhe J. Dimensional ridge alterations following tooth extraction. An experimental study in the dog. J Clin Periodontol. 2005;32(2):212-218.

3. Cardaropoli G, Araújo M, Lindhe J. Dynamics of bone tissue formation in tooth extraction sites. An experimental study in dogs. $J$ Clin Periodontol. 2003;30(9):809-818.

4. Schropp L, Wenzel A, Kostopoulos L, et al. Bone healing and soft tissue contour changes following single-tooth extraction: a clinical and radiographic 12-month prospective study. Int $J$ Periodontics Restorative Dent. 2003;23(4):313-323.
5. Reynolds MA, Aichelmann-Reidy ME, Branch-Mays GL. Regeneration of periodontal tissue: bone replacement grafts. Dent Clin North Am. 2010;54(1):55-71.

6. Casey DM, Lauciello FR. A review of the submerged-root concept. $J$ Prosthet Dent. 1980;43(2):128-132.

7. Hürzeler MB, Zuhr O, Schupbach P, et al. The socket-shield technique: a proof-of-principle report: The socket shield technique. $J$ Clin Periodontol. 2010;37(9):855-862.sss

8. Bäumer D, Zuhr O, Rebele S, et al. The socket-shield technique: first histological, clinical, and volumetrical observations after separation of the buccal tooth segment - a pilot study. Clin Implant Dent Relat Res. 2015;17(1):71-82.

9. Moharamzadeh K, Freeman C, Blackwood K. Processed bovine dentine as a bone substitute. Br J Oral Maxillofac Surg. 2008;46(2):110-113.

10. Koga T, Minamizato T, Kawai Y, et al. Bone Regeneration Using Dentin Matrix Depends on the Degree of Demineralization and Particle Size. PloS One. 2016;11(1):e0147235.

11. Nanci A, TenCate AR. Ten Cate's oral histology: development, structure, and function. 8th ed. St. Louis: Elsevier; 2013. 400 p.

12. Linde A. Dentin matrix proteins: composition and possible functions in calcification. Anat Rec. 1989;224(2):154-66.

13. Handschin AE, Egermann M, Trentz O, et al. Cbfa-1 (Runx-2) and osteocalcin expression by human osteoblasts in heparin osteoporosis in vitro. Clin Appl Thromb Off J Int Acad Clin Appl Thromb. 2006;12(4):465-472.

14. Valdec S, Pasic P, Soltermann A, et al. Alveolar ridge preservation with autologous particulated dentin — a case series. Int J Implant Dent. 2017;3(1).

15. Cardaropoli D, Nevins M, Schupbach P. New Bone Formation Using an Extracted Tooth as a Biomaterial: A Case Report with Histologic Evidence. Int J Periodontics Restorative Dent. 2019;39(2):157-163.

16. Angle E. Classification of the malocclusion. Dent Cosm. 1899;41:248267.

17. Miller TJ, Jeong HS, Davis K, et al. Evaluation of the American Society of Anesthesiologists Physical Status classification system in risk assessment for plastic and reconstructive surgery patients. Aesthet Surg J. 2014;34(3):448-456.

18. Samet N, Jotkowitz A. Classification and prognosis evaluation of individual teeth-A comprehensive approach. Quintessence Int. 2009;40(5):12

19. Glickman GN.AAE Consensus Conference on Diagnostic Terminology: background and perspectives. J Endod. 2009;35(12):1619-20.

20. Calvo-Guirado JL, Maté-Sánchez de Val JE, Ramos-Oltra ML, et al. The Use of Tooth Particles as a Biomaterial in Post-Extraction Sockets. Experimental Study in Dogs. Dent J. 2018;6;6(2).

21. Schwarz F, Golubovic V, Becker K, Mihatovic I. Extracted tooth roots used for lateral alveolar ridge augmentation: a proof-of-concept study. J Clin Periodontol. 2016;43(4):345-353. 